ISSN 1782-2041

DOI $10.25518 / 1782-2041.1229$

\title{
A Phenomenological Reading of the Many-Worlds Interpretation of Quantum Mechanics
}

\author{
JOAQUIN TRUJILLO \\ $\triangle$ jtrujillo1@me.com
}

\begin{abstract}
The articles provides a phenomenological reading of the ManyWorlds Interpretation (MWI) of quantum mechanics and its answer to the measurement problem, or the question of "why only one of a wave function's probable values is observed when the system is measured." Transcendentalphenomenological and hermeneutic-phenomenological approaches are employed. The project comprises four parts. Parts one and two review MWI and the standard (Copenhagen) interpretation of quantum mechanics. Part three reviews the phenomenologies. Part four deconstructs the hermeneutics of MWI. It agrees with the confidence the theory derives from its (1) unforgiving appropriation of the Schrödinger equation and (2) association of branching universes with the evolution of the wave function insofar as that understanding comes from the formalism itself. Part four also reveals the hermeneutical shortcomings of the standard interpretation.
\end{abstract}

Keywords quantum mechanics, measurement, transcendental phenomenology, hermeneutic phenomenology.

The Many-Worlds Interpretation (MWI) of quantum mechanics, the rendition of quantum mechanics discovered by theoretical physicist, Hugh Everett III, postulates a radical rendition of reality. MWI is an austere, unequivocal reading of the Schrödinger equation DeWitt calls "schizophrenia with a 
vengeance." It starts from the premise "all physical processes whatsoever are governed by the Schrödinger equation," 2 then purposefully executes the formalism to let it freely say from itself what the universe is doing, which is:

constantly splitting into a stupendous number of branches, all resulting from the measurement like interactions between its myriads of components. Moreover, every quantum transition, in every galaxy, in every star, in every remote corner of the universe is splitting our local world on earth into myriads of copies of itself. ${ }^{3}$

"Interpretation is an essential part of MWI." The theory contains a discrete hermeneutical point of departure. It begins from a unified conception of reality that contrasts the apparently dualistic perspective assumed by the Copenhagen interpretation of quantum mechanics, and stays the course of thinking it projects-open initially. The Copenhagen interpretation is considered the standard interpretation of quantum mechanics. "Many standard textbooks about quantum mechanics, and probably all popular-scientific treatments of the philosophy of quantum physics," as Friebe notes, "come to stop at the Copenhagen interpretation." MWI's answer to the measurement problem, or the question of "why only one of a wave function's probable values is observed when the system is measured," challenges the standard formulation, which some quantum physicists, including John Bell, contend has impeded efforts to investigate the foundations of quantum theory and understand the workings of the universe. ${ }^{6}$ Some quantum physicists have called MWI "ontologically extravagant" insofar as it invokes "an incredible number of unobservable worlds...to help explain observations within the single world to which we have access." Others, including Caltech theoretical physicist Sean Carroll, a supporter of

${ }^{1}$ Bryce S. DeWitt, “Quantum Mechanics and Reality,” Physics Today 23, no. 9 (1970), p. 33.

${ }^{2}$ David Z Albert and Barry Loewer, "Intepreting the Many Worlds Interpretation," Synthesis 77, no. 2 (1988), p. 203.

${ }^{3}$ DeWitt, "Quantum Mechanics and Reality," p. 33.

${ }^{4}$ Lev Vaidman, "On Schizophrenic Experiences of the Neutron or Why We Should Believe in the Many-Worlds Interpretation of Quantum Theory," International Studies in the Philosophy of Science 12, no. 3 (1998), p. 246.

${ }^{5}$ Cord Friebe, "The Measurement Problem. Minimal and Collapse Interpretations," in The Philosophy of Quantum Physics, ed. Cord Friebe, et al. (Cham: Springer, 2018), pp. 54-55.

6 John S. Bell, "Bertlmann's Socks and the Nature of Reality," in Speakable and Unspeakable in Quantum Mechanics: Collected Papers on Quantum Philosophy, ed. John. S. Bell (Cambridge: University Press, 1991). 
MWI, call the theory "ontologically restrained" insofar as it requires few "fundamental entities," which are, specifically: "a vector in Hilbert space and a single evolution law." Vaidman says MWI "explains the tremendous gap between what we experience as our world and what appears in the formalism of the quantum state of the universe." ${ }^{2}$ True. MWI unifies the understandings of the classical world and the quantum world by freeing the Schrödinger equation to answer the measurement problem.

The hermeneutics of MWI, indeed, of quantum physics generally, as London and Bauer imply in their phenomenologically sensitive treatment of quantum mechanics, ${ }^{3}$ begs phenomenological consideration. It contains open, fertile space for phenomenology - the method that strives to let phenomena

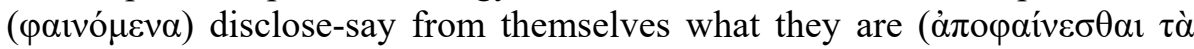

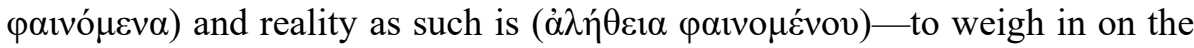
way the theory thinks the measurement problem and arrives at its revolutionary depiction of reality. This article responds to the invitation with a phenomenological reading of MWI. Its goal is to contribute to the valuation of the theory and maybe in some way offset the hermeneutical "naiveté" Deutsch says "prevails" in theoretical physics and has prevented some of its "most important theories from being properly understood and has seriously impeded progress." The "theories" Deutsch refers to fall under the rubric, "quantum mechanics." Quantum mechanics is the physics of the ultra-tiny. It is distinct from Newtonian mechanics, or the physics of classical reality, which is also the intuitively

\footnotetext{
${ }^{1}$ Sean M. Carroll and Charles T. Sebens, "Many Worlds, the Born Rule, and SelfLocating Uncertainty," in Quantum Theory: A Two-Time Success Story: Yakir Aharonov Festschrift, ed. Daniele C. Struppa and Jeffrey M. Tollaksen (Milano: Springer, 2014), pp. 159-160.

${ }^{2}$ Vaidman, "On Schizophrenic Experiences of the Neutron or Why We Should Believe in the Many-Worlds Interpretation of Quantum Theory," p. 246.

3 Steven French, "From a Lost History to a New Future: Is a Phenomenological Approach to Quantum Physics Viable?," in Phenomenological Approaches to Physics, ed. Harald A. Wiltsche and Phillip Berghofer (Cham: Springer, 2020); Fritz London and Edmond Bauer, "The Theory of Observation in Quantum Mechanics," in Quantum Theory and Measurement, ed. John Archibald Wheeler and Wojciech Hubert Zurek (Princeton: Princeton University Press, 1983).

${ }^{4}$ David Deutsch, “Comment on 'Many Minds' Interpretations of Quantum Mechanics by Michael Lockwood'," British Journal for the Philosophy of Science 47 (1996), p. 228.
} 
understood reality of everyday life. "Classical reality emerges from the substrate of quantum physics." Quantum mechanics explains this foundation and "is the most spectacularly successful theory ever devised." It contains a rub, however, as Deutsch implies. Quantum mechanics is hermeneutically challenged. Theoretical physicists have problems interpreting it. They either do not understand what the theory says or do not agree about what it says. ${ }^{3}$

This project is inspired by the interpretive questions surrounding MWI. It comprises four parts. Parts one and two review MWI and the standard interpretation of quantum mechanics. Part three describes the phenomenologies the project employs, which are, specifically, Husserl's transcendental-phenomenology and Heidegger's hermeneutic-phenomenology. Part four deconstructs the hermeneutics of the standard interpretation and MWI. MWI propositionally answers the measurement problem by way of its response to the standard interpretation. The two go hand in hand, which is why a phenomenological appraisal of the standard interpretation precedes the main analysis. It enhances efforts to exhibit the thinking MWI embodies.

\section{MWI}

MWI purports to dispel the question whether "particles," such as electrons, for example, a particle commonly discussed in popular quantum literature and the reference point for this analysis, are particles or waves. Particles are "all waves," as Carroll asserts. ${ }^{4}$ Waves (also quantum states) are more "fundamental" than particles, and their interpretation by the Schrödinger equation as wave functions provides "the best picture we currently have of what the universe is made of." "Everything at the tiniest levels is constituted by waves and evolves

\footnotetext{
${ }^{1}$ Wojciech H. Zurek, "Decoherence and the Transition from Quantum to Classical," Physics Today 44, no. 10 (1991), p. 43.

${ }^{2}$ Sean Carroll, Episode 63: Solo: Finding Gravity within Quantum Mechanics, podcast audio, Mindscape, 2019, https:/www.preposterousuniverse.com/podcast/2019/09/09/ 63-solo-finding-gravity-within-quantum-mechanics/.

${ }^{3}$ Ibid.; Sean Carroll, Sean Carroll: The Many Worlds of Quantum Mechanics, New Scientist, 2018, https://youtu.be/p7XIdFbCQyY.

${ }^{4}$ Episode 55: A Conversation with Rob Reid on Quantum Mechanics and Many Worlds, podcast audio, Mindscape, 2019, https://www.preposterousuniverse.com/ podcast/2019/07/15/55-a-conversation-with-rob-reid-on-quantum-mechanics-andmany-worlds/.

5 Something Deeply Hidden: Quantum Worlds and the Emergence of Spacetime (Dutton, 2019), p. 255.
} 
"according to the deterministic, linear Schrödinger equation,"1 or the "formalism of basic quantum mechanics" and the "quantum version" of Newtown's second law of motion. ${ }^{3}$ The wave function $(\Psi)$ signifies "the entire state of the particle," and "all fundamental concepts," including those pertaining to the classical world, are at their most basic level "wave-like and smooth" and evolve according to the Schrödinger equation. ${ }^{5}$

$$
i \hbar \frac{d}{d t}|\Psi\rangle=H|\Psi\rangle
$$

The Schrödinger equation, the "central equation" of quantum mechanics (i.e., quantum physics), has made quantum mechanics "the most successful theory in all of science."

The calculations enabled by the theory are astonishing in their range of applicability and the accuracy of their results. Quantum physics tells us how long it will take to heat up your frying pan to cook your eggs and how large a dying white dwarf star can be without collapsing. It reveals the exact shape of the double helix at the core of life, it tells us the age of the immortal cattle on the rock walls of Lascaux, it speaks of atoms split beneath the stone heart of Africa eons before Oppenheimer and the blinding light of Trinity. It predicts with uncanny accuracy the precise darkness of the blackest night. It shows us the history of the universe in a handful of dust. ${ }^{7}$

Probability is capital to the quantum mechanical understanding of the wave function and the foundation of the classical world. The Schrödinger equation is a linear, deterministic equation whose solutions are probabilistic. It univocally determines the evolution of a wave function's probable positions and

\footnotetext{
${ }^{1}$ Zurek, "Decoherence and the Transition from Quantum to Classical," p. 36.

2 Maximilian Schlosshauer, "Decoherence, the Measurement Problem, and Interpretations of Quantum Mechanics," Reviews of Modern Physics 76, no. 4 (2004), p. 1288.

${ }^{3}$ Carroll, Sean Carroll: The Many Worlds of Quantum Mechanics.

${ }^{4}$ Episode 63: Solo: Finding Gravity within Quantum Mechanics.

${ }^{5}$ H. Dieter Zeh, "Basic Concepts and Their Interpretation," in Decoherence and the Appearance of a Classical World in Quantum Theory, ed. Erick Joos, et al. (Heidelberg: Springer-Verlag, 2003), p. 31.

${ }^{6}$ Adam Becker, What Is Real? The Unfinished Quest for the Meaning of Quantum Mechanics (New York: Basic Books, 2018), pp. 1, 99.

${ }^{7}$ Ibid., p. 275.
} 
momentums. ${ }^{1}$ Probability is not "peripheral" to the formalism, but "absolutely at its core," 2 and, moreover, "no example of conflict between its predictions and experiment is known." ${ }^{3}$ The theory is "reliable" and "unforgiving." Its predictions always work and are always expected to work. ${ }^{4}$ The Schrödinger equation individuates particles, such as electrons, as wave functions, or quantum states, and deterministically projects their evolution through time. It does not discern them as specific points located at specific positions. It discerns them as clouds of probable positions (and momentums) that oscillate like waves. "An electron," or particle, as Carroll writes:

is in a superposition of every possible position we could see it in, and it doesn't snap into any specific location until we actually observer it to be there. 'Superposition' is the word physicists use to emphasize that the electron exists in a combination of all positions, with a particular amplitude [probability] for each one. Quantum reality is a wave function; classical positions and velocities are merely what we are able to observe when we prove that wave function. ${ }^{5}$

The electron normally maintains its coherence as a wave while it is situated within the relatively secure confines of the atom. There it evolves alongside other wave functions in a state of entanglement. Entanglement is the aggregate of superpositions that ensues among wave functions when they interact. It is the evolution of distinct quantum systems into "composite systems" such that changes in the evolution of any of the wave functions is instantaneously reflected in the other ones regardless the distance between them. Entanglement transmutes different interacting wave functions into coherent states of superposition. It transforms them into a composite of linear processes that deterministically evolves into the probabilities predicted by the Schrödinger equation. Wave functions have no semblance of particleness at this level of interaction.

\footnotetext{
${ }^{1}$ Mention of a particle's momentum is largely excluded from the analysis to enhance the project's interpretability. The omission is assessed to not detract from the argument and is consistent with general discussions about quantum mechanics.

${ }^{2}$ David Z Albert, Episode 45: David Albert on Quantum Mechanics and the Problems with Many-Worlds, podcast audio, Mindscape, 2019, https://www.preposterous universe.com/podcast/2019/03/04/episode-36-david-albert-on-quantummeasurement-and-the-problems-with-many-worlds/.

${ }^{3}$ Zurek, "Decoherence and the Transition from Quantum to Classical," p. 36.

${ }^{4}$ Carroll, Something Deeply Hidden: Quantum Worlds and the Emergence of Spacetime, p. 62.

${ }^{5}$ Ibid., p. 34

${ }^{6}$ Zeh, "Basic Concepts and Their Interpretation," p. 6.
} 
They do not have a specific position. They are the coherence of the probabilities of all of their positions.

Wave functions are observed as particles when they interact with a meaningfully larger environment, or "macroscopic" system, such as a measuring apparatus - "in the absence of a crisp criterion to distinguish between quantum and classical, an identification of the 'classical' with the 'macroscopic' has often been tentatively accepted." Macroscopic systems comprise their own wave functions and "are never isolated from their environments," however. They are continuous with the "one deterministically evolving quantum world," 3 as Zeh calls it and which MWI defines as the "wave function of the universe" or "universal wave function." MWI's reading of the Schrödinger equation contends the interaction between a wave function and a macroscopic system entangles them with each other, their environment, and, hence, the universal wave function. It further contends the entanglement of the quantum systems immediately invokes their decoherence, which "induces, in effect," as Zurek writes, "a superselection rule that prevents certain superpositions from being observed."4 That "rule," according to MWI, is the "splitting" or "branching" of the universe. The universal wave function evolves into one the probabilities comprised by the wave function it is entangled with and branches nearreplica universes for each of the other probabilities. The universe, including everything and everyone in it, branches near exact copies of itself. It splits in proportion to the number of probable values of the particular wave function such that each of the branched universes contains only one of the values. After branching, each of the probabilities exclusive of the one that is observed in the original universe is observed in its own universe and all the other respective probabilities vanish irreversibly. The original observer and everyone else in the universe branch too. A copy of them for each wave function value finds themselves in a branched universe with a "particular measurement outcome." These universes, the original and branched, as suggested by the mathematics, cannot access each other, however. They propositionally evolve into "neverto-interact-again worlds." They are "perceived separately as a consequence of their dynamical decoupling under decoherence," which, according to Zeh, may

\footnotetext{
${ }^{1}$ Zurek, "Decoherence and the Transition from Quantum to Classical," p. 36.

2 Ibid., p. 37.

${ }^{3}$ Zeh, "Basic Concepts and Their Interpretation," p. 24.

${ }^{4}$ Zurek, "Decoherence and the Transition from Quantum to Classical," p. 44.

5 Carroll, Something Deeply Hidden: Quantum Worlds and the Emergence of Spacetime, p. 119.

${ }^{6}$ Ibid., p. 117.
} 
be "the most fundamental irreversible process in Nature."1 Decoherence (branching) is "smooth" and "very fast." In fact, as proponents of the theory contend, it is so smooth and fast that we lack the ability to observe it experientially. ${ }^{2}$ Also, observers do not know into which universe they have branched until they register the value associated with a measurement outcome. ${ }^{3}$

An electron with two discrete positions, for example, spin up and spin down, is commonly referenced to elucidate the branching of the universe in accordance with the laws of the Schrödinger equation. The electron is in a superposition of both quantum states before it is observed, measured, or in any other way "disturbed" by a macroscopic system. Its position in this pure state is both spin-up and spin-down. Upon measurement, the wave function entangles with the measuring device, the observer, indeed, everything in the environment, and the universal wave function and the aggregate quantum system immediately decoheres and the universe splits. The original universe evolves to the value of the electron in either spin-up or spin-down position and branches a copy of itself that evolves to the value of the electron in the other position. The two universes are separate and reciprocally inaccessible, according to MWI. ${ }^{4}$ Moreover, the splitting-process, or "environmental decoherence," as Zeh calls it, "mimics quantum jumps," which means it is "continuous," "very fast," and the deterministic Schrödinger equation cannot "really describe" it. ${ }^{5}$

\footnotetext{
${ }^{1}$ Zeh, "Basic Concepts and Their Interpretation," p. 33.

${ }^{2}$ Ibid.; Vaidman, "On Schizophrenic Experiences of the Neutron or Why We Should Believe in the Many-Worlds Interpretation of Quantum Theory."; Charles T. Sebens and Sean M. Carroll, "Self-Locating Uncertainty and the Origin of Probability in Everettian Quantum Mechnics," The British Journal for the Philosophy of Science 69, no. 1 (2018); Carroll, Episode 63: Solo: Finding Gravity within Quantum Mechanics; Episode 55: A Conversation with Rob Reid on Quantum Mechanics and Many Worlds. ${ }^{3}$ Sebens and Carroll, "Self-Locating Uncertainty and the Origin of Probability in Everettian Quantum Mechnics."

${ }^{4}$ Carroll, Something Deeply Hidden: Quantum Worlds and the Emergence of Spacetime, pp. 114-117.
}

${ }^{5}$ H. Dieter Zeh, "Quantum Discreteness Is an Illusion," Foundation of Physics 40 (2010), pp. 1477-1478. 


\section{The standard interpretation}

The standard interpretation of quantum mechanics, the rendition of quantum theory generally associated with the Danish physicist Niels Bohr and his collaborators, including Werner Heisenberg, Wolfgang Pauli, and Max Born, proposes an understanding of the evolution of the wave function that is speciously more conservative than the one MWI purports. According to the standard interpretation, wave functions do not branch other universes when they decohere after entangling with a macroscopic system. They collapse into one of their probable values after they are disturbed (e.g., measured, observed). Moreover, because the standard interpretation alleges the wave function is "physically" or "objectively" inaccessible, it appropriates it solely as a mathematical formalism. It contends its significance is exclusively numerological or symbolic and nothing else can be inferred from it. Said another way, measuring or observing a wave function requires disturbing it, disturbing the wave function instantaneously collapses it into a single value, what is always measured or observed is a particular particle at a particular position, and, since wave functions are physically or objectively inaccessible, efforts to explore their foundations are meaningless. This is the interpretation of quantum mechanics generally associated with the standard formulation of the measurement problem, ${ }^{1}$ or the question of why only one of a wave function's probable values is observed when the system is measured.

The standard interpretation is not a historical artifact. It is considered "standard textbook quantum mechanics." ${ }^{2}$ Fuchs and Asher imply their subscription to it in their 2000 Physics Today article when they assert: "there is a temptation to believe that every quantum system has a wave function, even if the wave function is not explicitly known;" "no wave function exists either before or after we conduct an experiment;" the "wave function is not an objective entity;" "collapse is something that happens in our description of the system, not to the system itself;" and "the time dependence of the wave function does not represent the evolution of a physical system. It only gives the evolution of our probabilities for the outcomes of potential experiments on that system. This is the only meaning of the wave function." Anton Zeilinger implies a similar position when he remarks during a 2015 interview that "measurement

${ }^{1}$ Carroll, Something Deeply Hidden: Quantum Worlds and the Emergence of Spacetime, p. 23.

${ }^{2}$ Ibid., p. 23.

3 Christopher A. Fuchs and Asdher Peres, "Quantum Theory Needs No 'Interpretation'," Physics Today 53, no. 3 (2000), p. 71. 
results live in the classical world, and the quantum state is what we call a quantum world, which is only a mathematical representation." He goes on to say, while citing Heisenberg: "What you can talk about with your classical language, these are the objectively existing objects of the universe, these are classical objects. And that's it. That's what can be talked about. The rest is mathematics."

Bell disagreed deeply with this view. In his seminal 1980 article, ${ }^{2}$ the one that defined the experiment that falsified hypotheses nullifying the phenomenon of entanglement, he criticizes the standard interpretation for "making a virtue of necessity," assuming "positivistic and instrumentalist" prejudices, rejecting and disparaging efforts to develop a "coherent picture" of the quantum world, and asserting "atomic and subatomic particles do not have any definite properties in advance of observation." " N. David Mermin famously expresses a corresponding position.

I'm one of the uncomfortable ones. If I were forced to sum up in one sentence what the Copenhagen [standard] interpretation says to me, it would be "Shut up and calculate! But I won't shut up. I would rather celebrate the strangeness of quantum theory than deny it, because I believe it still has interesting things to teach us about how we think - about how certain powerful but flawed verbal and mental tools we once took for granted, continue to infect our thinking in subtly hidden ways. I don't think anybody, even Bohr, has done an adequate job of extracting these lessons. From this point of view the problem with the second generation's ironfistedly soothing attitude is that by striving to make quantum mechanics appear so ordinary, so sedately practical, so benignly humdrum, they deprive us of the stimulus for exploring some very intriguing questions about the limitations in how we think and how we are capable of apprehending the world. ${ }^{4}$

Everett conveys a similar perspective. He faults the standard interpretation for basing its rendition of reality on classical physics when quantum physics is universally understood to be more fundamental, and harboring "independent" postulates that proscribe efforts to investigate the foundations of the universe

\footnotetext{
1 Becker, What Is Real? The Unfinished Quest for the Meaning of Quantum Mechanics, p. 267.

2 Bell, "Bertlmann's Socks and the Nature of Reality."

${ }^{3}$ Ibid., p. 142.

${ }^{4}$ N. David Mermin, Boojums All the Way Through: Communicating Science in a Prosaic Age (Cambridge: Cambridge University Press, 1990), p. 199.
} 
quantum mechanically. ${ }^{1} \mathrm{He}$ calls the standard interpretation " "hopelessly incomplete because of it's a priori reliance on classical physics (excluding in principle any deduction of classical physics from quantum theory, or any adequate investigation of the measuring process)" "and "'a philosophical monstrosity" for disallowing the reality of the quantum world. ${ }^{2}$ Everett's point of departure is consistent with the arc posited by Einstein, one of the founders of quantum mechanics who not only contributed to the theory, but, according to Carroll, "also understood it better than anybody." ${ }^{3}$ Einstein (and Schrödinger) believed "quantum mechanics was incomplete as a theory of reality." 4 is view of the matter, as communicated in the landmark "Einstein-PodolskyRosen" ("EPR") paper, was this:

Any serious consideration of a physical theory must take into account the distinction between the objective reality, which is independent of any theory, and the physical concepts with which the theory operates. These concepts are intended to correspond with objective reality, and by means of these concepts we picture this reality to ourselves. ${ }^{5}$

Everett's approach to the measurement problem parallels the approach Einstein ultimately adopted to complete the General Theory of Relativity. He follows the mathematics. MWI shelves the metaphysics it associates with the standard interpretation and solves the measurement problem "through the mathematics of quantum physics itself." "The fundamental idea" of MWI is that all physical processes "must take place in accordance with the Schrödinger equation." "7 The theory answers the measurement problem by relying solely on the mathematics, letting the Schrödinger equation discharge the solution from itself, and refuting ad hoc propositions individuating "collapses" correlated to

${ }^{1}$ Carroll, Something Deeply Hidden: Quantum Worlds and the Emergence of Spacetime, p. 125.

2 Becker, What Is Real? The Unfinished Quest for the Meaning of Quantum Mechanics, p. 123.

${ }^{3}$ Carroll, Episode 55: A Conversation with Rob Reid on Quantum Mechanics and Many Worlds.

${ }^{4}$ Sean Carroll: The Many Worlds of Quantum Mechanics.

${ }^{5}$ Albert Einstein, Boris Podolsky, and Nathan Rosen, "Can Quantum-Mechanical Description of Physical Reality Be Considered Complete?," Physical Review 47 (1935), p. 777.

${ }^{6}$ Carroll, Something Deeply Hidden: Quantum Worlds and the Emergence of Spacetime, p. 117.

${ }^{7}$ Albert and Loewer, "Intepreting the Many Worlds Interpretation," p. 197. 
"measurements" or "observers." The wave function does not collapse, according to MWI. Its evolution always obeys the laws embodied in the Schrödinger equation, ${ }^{1}$ and no quantum formalism, including the Schrödinger equation, predicts wave function collapses. The mathematics are consistent, however, with the MWI thesis positing the decoherence of the wave function's combined superposition and the branching of the universal wave function into "an endless series" of "many worlds."

\section{Phenomenology}

This project renders the hermeneutics of MWI from the perspectives of Husserl's transcendental-phenomenology and Heidegger's hermeneutic-phenomenology. Although it could employ either perspective exclusively, as each stands on its own ground notwithstanding their fundamental relatedness, it assesses that appropriately applying both approaches augments the ability of phenomenology generally to illume MWI's hermeneutical start-point. The formula is not a prescription to combine the approaches. It is premised on the understanding the perspectives contain sufficient complementarity to warrant jointly employing them to deliver a more robust phenomenological reading of Everettian quantum mechanics than could be rendered by employing either one exclusively. This section reviews the phenomenologies. Its goal is to situate the main analysis, clarify the basis of its phenomenological assertions, and increase the project's availability to quantum physicists. Its purpose is also to explain its approach to students of the phenomenological movement. Phenomenologists often have their allegiances. They can be particular about the style of phenomenology employed. This article clarifies its approach to strengthen the project's falsifiability and increase its chances of receiving a fair hearing among phenomenological readers. Phenomenology is the rigorous, poetic (in

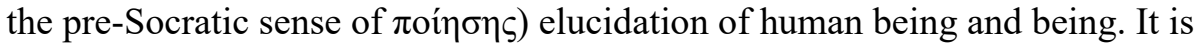
a method (and not a philosophy) that strives to exclude metaphysical notions from its analysis and let the phenomena it proposes to investigate usurp thinking. Like most empirical enterprises, including quantum mechanics, it has a lexicon appropriate to its matter. To dismiss its language as "jargon," as some physical scientists may be inclined to do, because it is unfamiliar is senseless.

${ }^{1}$ Carroll, Something Deeply Hidden: Quantum Worlds and the Emergence of Spacetime, p. 130.

2 Becker, What Is Real? The Unfinished Quest for the Meaning of Quantum Mechanics, p. 256. 
Also, to call phenomenological description "unempirical" because its assertions are elusive to statistical testing is scientistic. Phenomenology, like quantum mechanics, is part of the human endeavor to discover and know what things are and reality is. It labors to realize this project descriptively and interpretively. Its matter, human being and meaning, guarantees it will always come up short.

Husserl and Heidegger begin their phenomenologies with expositions of transcendence and always stay aligned with that course. Husserl frames his analysis of the phenomenon noetic-noematically. Transcendence, as he describes it, is the unity of the experiencing of and the experienced, of vónots (noesis) and vón $\mu \alpha$ (noema). It is consciousness as such (intentionality), or consciousness as always of something, namely, its "transcendent."1 Heidegger takes a distinct, but not unrelated, approach. He deconstructs transcendence ontologically, which, as indicated by the adverb's pre-Socratic roots,

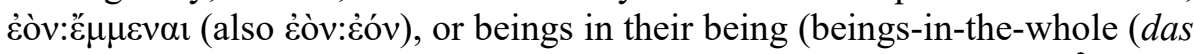

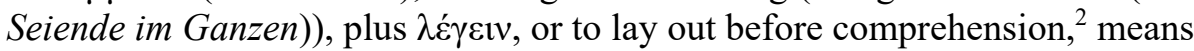
rendering it as Da-sein, paivó $\mu \varepsilon v o v$, or the World. Transcendence, thought hermeneutic-phenomenology, is the being-of-t/here, or "the manifest," as Emad calls it. ${ }^{3}$ It is the one World, or the unfolding totality of beings in their manifold differences and relatedness that each and every person $i s$.

Husserl and Heidegger's renditions of transcendence diverge direction-

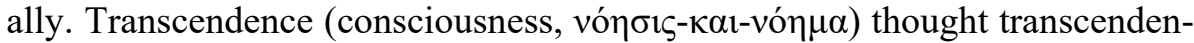
tal-phenomenologically is a disclosing-constituting process. It reveals the World - or, as Husserl describes it, which is distinct from Heidegger's interpretation, "the totality of objects that can be known through experience"

\footnotetext{
${ }^{1}$ Edmund Husserl, Ideas: General Introduction to Pure Phenomenology (London: George Allen \& Unwin Ltd, 1931), p. 130; Cartesian Meditations: An Introduction to Phenomenology, trans. Dorion Cairns (Dordrecht: Kluwer Academic Publishers, 1999), p. 33.

${ }^{2}$ Martin Heidegger, What Is Called Thinking?, trans. Fred D. Wieck and J. Glenn Gray (New York: Harper \& Row, Publisherd, 1968), pp. 198, 217-219, 223; Being and Time, trans. John Macquarrie and Edward Robinson (New York: Harper \& Row, Publishers, 1962), pp. 55-58; William J. Richardson, Heidegger: Through Phenomenology to Thought, 2nd ed. (The Hague: Martinus Nijhoff, 1967), p. 56.

${ }^{3}$ Parvis Emad, On the Way to Heidegger's Contributions to Philosophy (Madison: The University of Wisconsin Press, 2007), p. 3.

${ }^{4}$ Husserl, Ideas: General Introduction to Pure Phenomenology, p. 52.
} 
and imbues it with meaning. The World, also, as understood by way of Husserl, "total world-phenomenon"1 and "the world constantly given to us as actual in our concrete world-life" (Lebenswelt), is simply t/here, given to consciousness. ${ }^{3}$ It is the world of " "wakeful' living," "the world as immediately given to me," and "the world in which I find myself and which is also my worldabout-me" and "holds good" for all other persons whom I find "present" in it. ${ }^{4}$ The meaning it is and the ones it encompasses, the significations that say from experience what this or that phenomenon is, however, are constituted. They are articulated in consciousness by the transcendental ego, which, according to Husserl, is the primordial source of all knowing and experiencing.

Transcendental-phenomenology endeavors to exhibit intentionality and constitution through a series of professed methodological steps Husserl calls, "reductions." Reduction is the method transcendental-phenomenology employs to position the thinker to exhibit experience rigorously by intuiting it "as it gives itself out to be." Husserl distinguishes three types of reduction. The first is phenomenological reduction. It labors to suspend the natural thesis ("general thesis of the natural standpoint"), ${ }^{6}$ or the taken-for-granted mode of experiencing and understanding through which the World is commonly endured. The World lived through the natural thesis (attitude), as Schutz describes it, is the World "common to all of us," wherein "we have not a theoretical but an eminently practical interest." It is the "world of everyday life" and "the scene and also the object of our actions and interactions." It is the World we have to "dominate" and "change" to "realize the purposes we pursue within it among our fellow-men." It is the World where "we work and operate not only within but upon." It is also the start-point of the perspective of classical physics. It is the World taken-for-granted as a discrete (local) place of discrete subjects and discrete objects and the World that subscribes to commonsense notions of causality. The classical perspective is framed within the natural thesis. It belongs to it.

${ }^{1}$ Cartesian Meditations: An Introduction to Phenomenology, p. 93.

2 The Crisis of European Sciences and Transcendental Phenomenology: An Introduction to Phenomenological Philosophy, trans. David Carr (Evanston: Northwestern University Press, 1970), p. 93.

${ }^{3}$ Ideas: General Introduction to Pure Phenomenology, p. 58.

${ }^{4}$ Ibid., pp. 103-106.

${ }^{5}$ Ibid., p. 92.

${ }^{6}$ Ibid., p. 106.

${ }^{7}$ Alfred Schutz, "On Multiple Realities," Philosophy and Phenomenological Research 5, no. 4 (1945), p. 534. 
Phenomenological reduction provisionally revokes the thinker's membership in the natural thesis so the World may present itself in its selfgivenness, according to transcendental-phenomenology. The reduction suspends participation in the everyday meanings that distinguish the World of everyday life so it may come clearly into view. It puts the intentions that constitute its meaning "out of action" so the World may show itself from itself as it originarily is. ${ }^{1}$ Phenomenological reduction also delivers the thinker, according to Husserl, to the possibility of a second, "eidetic" reduction. ${ }^{2}$ Eidetic reduction throws the intentions (intentional or intending meaning processes) through which the World is understood and lived into relief, frees the thinker to make them an object of his thinking, and thereby augments his ability to exhibit them. The third and final reduction Husserl posits is a transcendental reduction. ${ }^{3}$ It purportedly individuates the source of intentionality and constitution, or the "transcendental ego." including ideas and fantasies) and intentionality (experiencing as such) transports thinking to the threshold of the transcendental ego, which Husserl denotes as the ground of knowledge, intentionality, and constitution, and allows the thinker to make it an object of phenomenological interrogation. ${ }^{5}$ Husserl calls the transcendental ego "the pole of identity," the primordial "I, who lives through this and that subjective process [experiencing] ... as the same I," and the "transcendental concrete I-myself." As he sees it, according to Nakhnikian, the World "cannot be thought of except as being "constituted by the transcendental ego's intentional acts." "7 Transcendental reduction is postulated to yield the possibility of exposing the basis of consciousness and experiencing to intentionality.

Hermeneutic-phenomenology contains no notions of constitution or a transcendental ego. Da-sein, as Heidegger propositionally exhibits it, is the World. It is the being-of-t/here, or, perhaps more telling, the being-of-thet/here. Hermeneutic-phenomenology exposes Da-sein two ways, transcendental-horizonally and being-historically. The first perspective, as witnessed in Being and Time, thinks Da-sein in relation to being. The second perspective,

\footnotetext{
${ }^{1}$ Husserl, Ideas: General Introduction to Pure Phenomenology, pp. 106-109.

2 Ibid., pp. 57-60, 114, 147-148; George Nakhnikian, "Introduction," in The Idea of Phenomenology (Dordrecht: Kluwer Academic Press, 1990), pp. xvii-xviii.

3 "Introduction," p. xix.

${ }^{4}$ Husserl, Cartesian Meditations: An Introduction to Phenomenology, p. 90, 93-95.

${ }^{5}$ The Idea of Phenomenology, trans. William P. Alston and George Nakhnikian (Dordrecht: Kluwer Academic Press, 1990).

${ }^{6}$ Cartesian Meditations: An Introduction to Phenomenology, pp. 65-66, 93.

${ }^{7}$ Nakhnikian, "Introduction," p. xx.
} 
as seen in Contributions to Philosophy (From Enowning) ${ }^{1}$ and Mindfulness, ${ }^{2}$ elucidates be-ing (Seyn), or enowning (Ereignis), in relation to Da-sein. Heidegger denotes being (Sein) as be-ing (Seyn) in the being-historical perspective to clarify it as a matter to be thought. This project will largely use the common spelling (being) to simplify its argument. Hermeneutic-phenomenology, specifically the transcendental-horizonal perspective, is inspired by Husserl's early writings but circumvents his later theses by defining phenomenology as an endeavor to inabide (find abode in) (Inständigkeit) the truth of phenomena, including the phenomenon of being, where truth signifies nothing metaphysical, axiological, ideological, or theological, but, rather, the pre-Socratic (pre-philosophical), $\dot{\alpha} \lambda \dot{\eta} \theta \varepsilon 1 \alpha$. This notion of truth, $\dot{\alpha} \lambda \dot{\eta} \theta \varepsilon 1 \alpha$, signifies nothing pure or absolute. Hermeneutic-phenomenology posits an essential or ownmost (Wesen) meaning of phenomena, which it corresponds with their truth, but does not postulate any "pure essence" of phenomena, as Husserl does. ${ }^{3}$ Truth also is not a being, or thing, although it can be a matter of thinking. Truth, thought hermeneutic-phenomenologically, is a disclosing-concealingsheltering process and commensurate with the word, "is." The being-historical rendition of "is," which is always ultimately thought in relation to Da-sein (the World) ${ }^{4}$ and Heidegger also calls, "enowning," reveals beings, conceals beings, or shows their meaning as staying away. It is a back-and-forth struggle between the phenomena of disclosing and concealing as conveyed by $\dot{\alpha} \lambda \eta \dot{\theta} \theta \varepsilon 1 \alpha$ 's $\alpha$-privativum and its root, $\lambda \dot{\eta} \theta \eta$, which signifies nothingness (also $\chi \alpha \dot{\alpha} \varsigma)$, such that " $\lambda \dot{\eta} \theta \eta$ not only is prior to $\dot{\alpha} \lambda \dot{\eta} \theta \varepsilon 1 \alpha$ but remains intrinsic to it at all times." The phenomenon of truth, thought hermeneutic-phenomenologically, or $\dot{\alpha} \lambda \dot{\eta} \theta \varepsilon 1 \alpha$, is another name for being, and errancy (Irre) is ingredient to it. $^{6}$

Hermeneutic-phenomenology does not propose to come to the truth of things or being via any reduction, although the transformation is not alien to

\footnotetext{
${ }^{1}$ Martin Heidegger, Contributions to Philosophy (from Enowning), trans. Parvis Emad and Kenneth Maly (Bloomington: Indiana University Press, 1999).

2 Mindfulness, trans. Parvis Emad and Thomas Kalary (London: Continuum International Publishing Group, 2006).

${ }^{3}$ Husserl, The Idea of Phenomenology, pp. 55-57.

${ }^{4}$ Parvis Emad, "On the Inception of Being-Historical Thinking and Its Unfolding as Mindfulness," Heidegger Studies 16 (2000).

${ }^{5}$ Richardson, Heidegger: Through Phenomenology to Thought, p. 492.

${ }^{6}$ Heidegger, Contributions to Philosophy (from Enowning), p. 244; Mindfulness, pp. 8, 441; Frank Schalow, "Introduction," in Heidegger, Translation, and the Task of Thinking: Essays in Honor of Parvis Emad, ed. Frank Schalow, Contributions to Phenomenology (New York: Springer, 2011), p. 31.
} 
the way to truth, but, rather, by resolutely yielding thinking to their being or, in the case of being, which is not a thing, to being itself (be-ing). It also does not posit a transcendental ego or any type of self in the Cartesian sense. It discloses a "mineness" ("selfhood") 1 inasmuch as "Da-sein is always mine," 2 and a " for-the-sake-of-which to which every 'towards-which' ultimately goes back,"”3 but no primordial "I" or Cartesian "self." The ownmost or essential meaning of being human, of Da-sein, aside from the primordial concern for being (Sorge), is the $t /$ here of its to be, according to hermeneutic-phenomenology. Human being is t/here-being. It is the coming-to-pass of the World, which is the being and meaning of things, ${ }^{4}$ or their thingness. Da-sein is, with all its starts and stops, or "stumblings" (Umstürze), as Heidegger describes it, the truth of things. ${ }^{5}$ It is the clearing of the self-concealing-withdrawing.

Hermeneutic-phenomenology, like transcendental-phenomenology, aims at the free disclosure of phenomena. It proposes to accomplish its purpose, or at least try to, through thinking (and language), or thinking as such, which is not equal to rationalizing, logic, or calculation, although it can include them. Thinking, thought hermeneutic-phenomenologically, is resolutely relinquishing $\lambda$ ó ${ }_{0} \varsigma-D a$-sein's innate potentiality to comprehend being and meaning and render phenomena through words - to the truth of its matter. It is an attuning-receiving-discovering process, a listening and heeding that lets phenomena steer $\lambda$ ó o $_{\text {o }}$ toward letting them disclose-say themselves. It is a transformation hermeneutic-phenomenology discerns as "projecting-open" (Entwerfen) ${ }^{6}$ and "inceptional thinking,"7 as implied by the aphorism, "to the things themselves!" ${ }^{1}$ It is, as Heidegger describes it in his being-historical writings, the process whereby "what is opened up in the projecting-open overwhelms the projecting-open itself and rectifies it," a "crossing" whereby "every step is born up by the question of the truth of be-ing," 10 a "grounding-

${ }^{1}$ Heidegger, Being and Time, pp. 68, 262, 365-366, 369; Contributions to Philosophy (from Enowning), p. 224.

${ }^{2}$ Contributions to Philosophy (from Enowning), p. 47.

${ }^{3}$ Being and Time, pp. 116-117.

${ }^{4}$ George Kovacs, Thinking and Be-Ing in Heidegger's Beiträge Zur Philosophi (Vom

Ereignis) (Bucharest: Zeta Books, 2015), p. 269.

${ }^{5}$ Heidegger, Contributions to Philosophy (from Enowning), pp. 58-59.

${ }^{6}$ Ibid.

7 Kovacs, Thinking and Be-Ing in Heidegger's Beiträge Zur Philosophie (Vom

Ereignis).

${ }^{8}$ Heidegger, Being and Time, p. 58.

${ }^{9}$ Contributions to Philosophy (from Enowning), p. 39.

${ }^{10}$ Ibid., p. 48. 
attunement" and "fierce steadfastness" to dwell in the truth, ${ }^{1}$ a movedness that "does not come to a stop," ${ }^{2}$ and a relinquishing of "every semblance of selfempowerment, without every becoming self-effacement and surrender."

This project refrains from discussions of a transcendental ego. It assesses the trajectory would undermine its empirical aims. Husserl's writings about the transcendental ego, his individuation of the phenomenon as the ground of intentionality and constitution, has drawn censures of radical subjectivism and "subjective idealism." ${ }^{4}$ Husserl admits this, ${ }^{5}$ and the criticisms are not unwarranted. Discussions of a transcendental ego are remarkably susceptible to bias and solipsism. They also yield little evidence that can be intersubjectively or hermeneutically corroborated. The transcendental ego is not something $\mathrm{t} / \mathrm{h}$ ere that can be openly assessed and talked about. Transcendentalphenomenology also draws fire for individuating phenomena, including the transcendental ego, as absolutes, and mention of them in those terms are excluded from the analysis too. Phenomenology, regardless the perspective, is not about disclosing absolutes. It is an endeavor. It is a possibility that is never fulfilled and a process always underway. It is its task: the rigorous exposition of phenomena. Any aspirations transcendental-phenomenology may profess about suspending the natural thesis, about bracketing the spontaneous or automatic belief in the status of the World, or reducing phenomena to arrive at their absolute truth, are challenged by Da-sein's facticity, by "the way Dasein is (lives) in the world, in life." The phenomenal body, the only real body found in transcendental reduction, as Husserl describes it, ${ }^{7}$ and the "total awareness of my posture in the intersensory world," as described by Merleau-Ponty, ${ }^{8}$ illustrates this point. The primordial meanings of breathing, tactility, and spatiality bridle efforts to suspend participation in the natural thesis or achieve a complete reduction of any type.

The hermeneutical constraints continuous with facticity do not negate transcendental-phenomenology's empirical value. The scientific relevance of

\footnotetext{
${ }^{1}$ Ibid., p. 24; Heidegger, Mindfulness, p. 239.

${ }^{2}$ Contributions to Philosophy (from Enowning), p. 40.

${ }^{3}$ Ibid., p. 39.

${ }^{4}$ Nakhnikian, "Introduction," p. xx.

${ }^{5}$ Husserl, Ideas: General Introduction to Pure Phenomenology, p, 18; Cartesian Meditations: An Introduction to Phenomenology, p. 148.

${ }^{6}$ George Kovacs, "The Idea of Hermeneutics in Heidegger," Existentia 10, no. 1-4 (2000), p. 44.

${ }^{7}$ Husserl, Cartesian Meditations: An Introduction to Phenomenology, pp. 110-111.

${ }^{8}$ Maurice Merleau-Ponty, Phenomenology of Perception, trans. Colin Smith (London: Routledge \& Kegan Paul, 1962), p. 110.
} 
the reduction, regardless the target, and as it pertains to this project, are twofold. First, it frees thinking to increase its ability to neutralize, control, or mitigate the prejudices and prejudgments implicit to thinking, experiencing, and

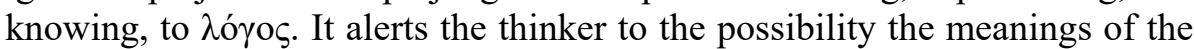
things he intuits are not immanent to their thingness, but, rather, are effected by decision, choice, habit, or bias. It makes intentionality and thinking suspect to thinking by forewarning the thinker to the possibility either (or both) is betraying the struggle to inabide the truth of phenomena. Second, the reduction frees thinking to make intentionality an object of thinking. It augments the power of thinking to exhibit consciousness by referentially throwing intentionality into relief and illuminating the way one goes about exposing it. It frames consciousness and experience within a perspective that helps open the way for phenomena to be rigorously thought.

Transcendental-phenomenology, despite Husserl's claims of producing a foundational science of consciousness that brings "truly absolute" data of experiencing or "pure" phenomena to light, ${ }^{1}$ no matter how much Husserl may explain otherwise, as he does when he professes to transmute thinking to a "universe of absolute freedom from prejudice," is a hermeneutical endeavor. It, and every other version of phenomenology, is inescapably situated within Da-sein's facticity. It, as an expression of thinking, regardless the matter, is ineluctably invoked and invariably shaped by the "practical concern about the way of [human] being and knowing in the world." It always relates to human existence and is subject to the factical constraints endemic to transcendence. The reduction is a project, an endeavor, a striving of human being and not a transfiguration of consciousness or transcendence. It is a systematic and scrupulous effort to control the assumptions, beliefs, or ideas that may obfuscate the self-givenness of phenomena and impede efforts to know them as they show themselves to be from themselves.

This project also restrains from employing hermeneutic-phenomenology's full interpretive range, and largely remains within the transcendentalhorizonal perspective, at least explicitly. Transcendental-horizonal and beinghistorical perspectives are not disconnected from each other. They signify a single course of thinking. The latter unfolds from the former, as Emad correctly explains, ${ }^{4}$ and ultimately circles back to a fuller exposition of Da-sein.

\footnotetext{
${ }^{1}$ Husserl, The Idea of Phenomenology, p. 5.

${ }^{2}$ Cartesian Meditations: An Introduction to Phenomenology, p. 35.

${ }^{3}$ Kovacs, "The Idea of Hermeneutics in Heidegger," p. 42.

4 Emad, "On the Inception of Being-Historical Thinking and Its Unfolding as Mindfulness," p. 55.
} 
Exercising either perspective exclusive of the other alienates the thinker from hermeneutic-phenomenology's full disclosing-saying power. This project generously employs the being-historical interpretation of thinking, but withholds discussions of be-ing (enowning) or the correlation of be-ing to truth $(\dot{\alpha} \lambda \dot{\eta} \theta \varepsilon 1 \alpha)$. It assesses that a complete treatment of the phenomena as they relate to MWI, the standard interpretation, or the measurement problem would dilute its effort to realize its objectives. The hermeneutical-phenomenological rendition of truth is confined here to signify the ownmost, essential, or originary meaning of a matter. This perspective is attuned to the meaning of "is" as the essential sway ( $\dot{\alpha} \lambda \dot{\eta} \theta \varepsilon ı \alpha$, enowning) that illuminates beings (renders them from their self-concealment) and binds them into a whole, but leans toward the

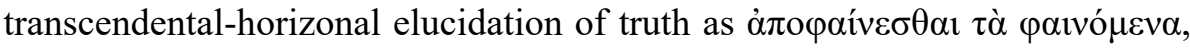
or the way things freely show themselves from themselves in Da-sein.

\section{The hermeneutics of quantum mechanics}

The wave function, as discerned by the Schrödinger equation, is a phenomenon. It contains its ownmost meaning. Any difficulties associated with rendering it are hermeneutical. They are interpretive. The "problem" of the measurement problem, the question of why only one of a wave function's probable values is observed when the system is measured, is not immanent to the phenomenon of the wave function as it shows itself from itself, again, through the Schrödinger formalism. It is a human question and a human problem. London and Bauer imply a commensurate thesis when they identify in the observer the "right to create his own objectivity" and "cut the chain of statistical correlations" disclosed by the Schrödinger equation. ${ }^{1}$ The problem of the measurement problem does not, rendered transcendental-phenomenologically, apodic-

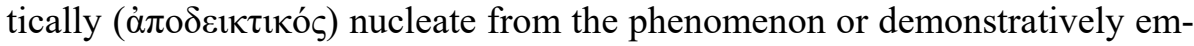
anate from its essential meaning. It is a distinct, although not unrelated, meaning that centers on an idea, understanding, signification, or decision sourced to intentional constitution and whose center of gravity is located within the noetic dimensions of consciousness. It is a meaning constituted by consciousness in the natural thesis. It is a hermeneutical outcome of the everyday, human encounter with the quantum world. It does not, thought hermeneutic-phenomenologically, belong to the essential meaning of the mathematical rendition of the wave function. It is a problematic Zeh says arises when one "insists" on a

${ }^{1}$ London and Bauer, "The Theory of Observation in Quantum Mechanics." 
"classical" understanding of "physical reality,"1 or on an interpretation of the World based on taken-for-granted, commonsense notions of locality framed within the natural thesis.

A basic reading of the standard interpretation says wave functions collapse into one of the probabilities they comprise when they are measured, which implies observed. Carroll correctly points out "the idea of collapse of the wave function upon making an observation is at the heart of what's called the Copenhagen interpretation of quantum mechanics," ${ }^{2}$ but also correctly notes, "there is no separate rule governing 'wave function collapse." 3 There is the wave function, which is a superposition of probable states, and its evolution as rendered by the Schrödinger equation. ${ }^{4}$ That's it. This is the originary meaning of a particle. The standard interpretation ascribes the notion of "collapse" to the evolution of the wave function, and can be reduced to omit mention of it, especially since the perspective commonly chooses not to investigate its foundations, by rendering it this way: "only one of the values a wave function comprises is observed when the system is measured." This iteration is simpler than the one commonly associated with the standard interpretation and does not diverge from basic meaning of the wave function. It shows beyond Carroll's rendition of the problem that the notion of "collapse" is superfluous, meaning, quantum mechanics does not require it to accomplish its empirical objectives. The meaning of "collapse," interpreted transcendental-phenomenologically, is generated. It is ad hoc, or metaphysical, an abstraction imputed to the meaning of the wave function by consciousness. It is an artifact of consciousness and not given with the originary significance of the wave function, but, rather, ascribed to it to render the phenomenon "classically," which is also to say, transcendental-phenomenologically, in accordance with the natural thesis.

Reducing the standard interpretation to its basic meaning also throws the notions of "measure" and "observed" into relief. Their status is ambiguous. What do "measured" and "observed" mean? What types of measurement or observation do they imply? Clearly it is a person enacting the measurement, because only human beings measure things. It is also a person who is doing the observation, which, in the context of the standard formulation means interpretation, and only human beings do that too. Measurement and interpretation

\footnotetext{
${ }^{1}$ Zeh, "Quantum Discreteness Is an Illusion," p. 1492.

${ }^{2}$ Carroll, Episode 63: Solo: Finding Gravity within Quantum Mechanics.

${ }^{3}$ Carroll and Sebens, "Many Worlds, the Born Rule, and Self-Locating Uncertainty," p. 158.

${ }^{4}$ Carroll, Episode 63: Solo: Finding Gravity within Quantum Mechanics.
} 
are expressions of $\lambda$ ó $\gamma \circ \varsigma$, the intrinsic power of $D a$-sein to comprehend being and beings and render their meaning through words. They are ways $D a$-sein understands the World and, hence, itself. They reflect ways Da-sein comprehends "is." Reduced to their fundamental significance, "measured" and "observed" signify macroscopic or environmental referents relative to the evolution of the wave function. They hermeneutically frame the individuation of the quantum state, which London and Bauer denote as $\Psi(x, y, z)$, or the "combined system" consisting of "the actual object $x$," or wave function, "the apparatus $y$, and the observer $z$," without knowing "in what state the object $x$ is." reduced iteration of the standard interpretation also reveals the self-givenness of "measured" and "observed" to be aligned with MWI, which interprets the evolution of the wave function in relation to a macroscopic system and the superposition and decoherence of the aggregate quantum state. The common rendition of the standard interpretation in its original form does not intend "measured" and "observed" this way, however. It intends them as local transformations, acts, or objects associated with local subjects. Their meanings belong to the sphere of classical physics. Assessed transcendental-phenomenologically, they are significations generated within intentionality that conform the understanding of the quantum state to the classical understanding of reality and the natural thesis. Their meaning, like that of wave function collapse, are constituted in consciousness, do not belong to the originary meaning of the wave function as revealed by the Schrödinger equation, and, according to Zeh, are part of the "misconceptions and misnomers that are popular in quantum theory." 2

The Schrödinger equation also does not say wave functions are unavailable to the classical world nor anything along the lines of the views Bohr expressed that are commonly associated with the standard interpretation, as instanced when he replies to the question whether the formalism denotes an "underlying quantum reality," with: "There is no quantum world. There is only an abstract quantum physical description. It is wrong to think that the task of physics is to find out how nature is. Physics concerns what we can say about nature." 3 The Schrödinger equation also does not convey from itself anything commensurate with John Wheeler's iteration of Bohr's view, which he calls "the usual Copenhagen pragmatism" and says amounts to the position: "'better no reality at all than a nonlocal [quantum] one.",4 According to Wheeler:

\footnotetext{
${ }^{1}$ London and Bauer, "The Theory of Observation in Quantum Mechanics," p. 252.

${ }^{2}$ Zeh, "Quantum Discreteness Is an Illusion," p. 1478.

${ }^{3}$ Bell, "Bertlmann's Socks and the Nature of Reality," p. 142.

${ }^{4}$ Zeh, "Quantum Discreteness Is an Illusion," pp. 1488-1489.
} 
if Bohr's position could be summarized today, no elementary quantum phenomenon is a phenomenon until it has been brought to a close by an irreversible act of amplification, like the triggering of a Geiger counter, or the click of a photo detector, or the blackening of a grain of photographic emulsion. Until that happens, this phenomenon to be is not yet a phenomenon. It's a like a great smoky dragon that has no position in space, no location in time. You know only the tail where the quantum or the photon or the electron or [whatever particle] you're dealing with entered the equipment [detector], but until the dragon has bit with its teeth one counter or the other you have no right to speak of where it is or what it's doing. It's the strangest thing in this strange world, this elementary quantum phenomenon of Niels Bohr. And yet, of all the things we've learned, it is the central point and lesson of $20^{\text {th }}$ century physics. ${ }^{1}$

Thinking the originary meaning of the wave function transcendental-phenomenologically corresponds the difference between the self-givenness of the phenomenon and the meanings the standard interpretation commonly associates with it to a hermeneutical point of departure immersed in the natural thesis. The World endured through this perspective is the life-world of the natural attitude. It is the commonsense World of everyday causality and the sphere of classical physics. It is a discrete World of discrete persons and objects possessing discrete positions and velocities, a concrete World where persons and things are definitively $t /$ here and only t/here, in "phase space," or the space where each possible state of an entity corresponds to a specific vector in spacetime. Quantum mechanics, which is formulated in Hilbert space $(H)$, a mathematically derived infinite-dimensional, abstract vector space that theoretically frames a wave function's evolution, does not subscribe to the presumptions embodied in the natural thesis, and, hence, as Zurek notes, is unable "to provide a natural framework that can accommodate our prejudices about the workings of the universe." It opposes what Everett's says is the standard interpretation's "strong reliance upon the classical level from the outset." It contests an interpretive start-point that, he continues:

precludes any possibility of explaining this [quantum] level on the basis of an underlying quantum theory. (The deduction of classical phenomena from quantum theory is impossible simply because no meaningful statements can be made without pre-existing classical apparatus to serve as a reference frame.) The

\footnotetext{
${ }^{1}$ Lars Becker-Larsen, “Atomic Physics and Reality,” (Denmark1985).

${ }^{2}$ Zurek, "Decoherence and the Transition from Quantum to Classical," p. 36.
} 
[standard] interpretation suffers from the dualism of adhering to a "reality" concept (i.e., the possibility of objective description) on the classical level but renouncing the same in the quantum domain. ${ }^{1}$

A hermeneutic-phenomenological reading of the standard interpretation distinguishes two phenomena that appear to be holding sway in its response to the measurement problem. Both are associated with Da-sein's profound finitude. ${ }^{2}$ The first is the limitations intrinsic to Da-sein's power to comprehend being, and, hence, beings and beings-in-the-whole. The second is $D a$ sein's factical dependence on beings. Da-sein's comprehension of being, a potentiality it corresponds with $\lambda$ ó $\gamma \circ \varsigma$, is innately incomplete. Errancy is ingredient to it. Da-sein may be the being-of-t/here and the clearing itself, ${ }^{3}$ but it is not omniscient. Da-sein is not an "all-seeing," "all-knowing," "all-experiencing," or "never-erring" t/here-being. It is internally constrained by its limited capacities to think, experience, perceive, and comprehend. It must conscientiously (resolutely, openly, freely, responsibly) labor to extend the horizons of its disclosing-saying power and strive to overcome itself to think and know. It is compelled to dispel or surmount prejudgments, prejudices, and everyday human inclinations (e.g., indolence, obtuseness, short-sightedness, self-absorption, practicality) common to the human situation and that thwart its potentiality to dwell in the truth of phenomena.

The standard interpretation appears to be shaped by lapses in thinking that are consistent with the inherent limitations of $\lambda$ ó $\gamma \circ \varsigma$ to comprehend and its intrinsic proclivity to err. The formulation asserts wave functions are unavailable to "physical" or "objective" access rather than adopting the more parsimonious understanding they surpass the threshold of human experiencing. Assessed phenomenologically, the standard interpretation projects metaphysical notions to speciously complete an incomplete understanding of the wave function and render it in classical terms rather than letting the ownmost of the Schrödinger equation dominate its comprehension of the quantum state. It adheres to a metaphysics, forgoes thinking the wave function further, and disparages efforts to investigate its foundations. None of these decisions reflect the self-givenness of the wave function as rendered by the Schrödinger equation.

\footnotetext{
${ }^{1}$ Hugh Everett, "The Theory of the Universal Wave Function," in The Many Worlds Interpretation of Quantum Mechanics, ed. Bryce S. DeWitt and Neill Graham (Princeton: Princeton University Press, 1973), p. 111.

${ }^{2}$ Richardson, Heidegger: Through Phenomenology to Thought, p. 38.

${ }^{3}$ Thomas Kalary and Frank Schalow, "Attunement, Discourse, and the Onefold of Hermeneutic Phenomenology: Recent Heidegger-Literature and a New Translation of His Work in Critical Perspective," Heidegger Studies 27 (2011), pp. 201-202.
} 
All of them alienate the thinker from the truth of the reality illuminated by the quantum formalism, from the ability of the equation to disclose-say what the wave function is doing. None of the trajectories are uncommon. All of them are consistent with the limitations and errancy intrinsic to $\lambda$ ó ${ }_{0} \varsigma$ and the shortcomings ingredient to thinking. They reveal the standard formulation as a form of hermeneutical or intellectual escapism, or both, that essentially says: "thinking the matter stops at 'measurement' and 'observation," which are notions that are grounded in classical conception of reality, "and there is no need to think them further." They suggest the standard interpretation contains the inclination to not think the question of the evolution wave function and instead to default to a classical rendition of the transformation.

A particle is not a "phenomenon to be" or "not yet a phenomenon" before a wave function is disturbed, as Bohr asserts. The propositions are senseless. There is no mathematical or experimental evidence to the support them. The universe is all there is and there are no quantum or phenomenological data, including that rendered being-historically, suggesting wave functions do not belong to it or particles are "not yet phenomena" until wave functions are disturbed. A particle, the particular position of a quantum state one observes when a wave function is disturbed, thought phenomenologically, is an aspect of the wave function that has come into the range of human experiencing. This assertion does not mean, as Lurçat intimates in a less frugal solution he derives phenomenologically, it has arrived from a "different" region of reality. ${ }^{1}$ The difference between the postulates is subtle but not insignificant. Lurçat's says there is one reality and implies it is arranged into distinct spheres. It imputes an idea onto reality as such ( $\varphi \alpha v o ́ \mu \varepsilon v o v)$. The view advanced here says there is one reality, but $\lambda$ ó $\gamma$ o $\zeta$ lacks the capacity to experience all of it. This perspective boosts (within the constraints of language) the phenomenological resistance to impute ideas to phenomena and is more aligned with the meaning of the double-negative. It is also consistent with the basic quantum mechanical depiction of reality, which says, according to Carroll, "there is an unmistakable, irreducible inability to exactly observe a quantum system." ${ }^{\text {It }}$ is the limitations intrinsic to $\lambda$ óyos, to the power of Da-sein to experience, comprehend, and know being, beings, and beings-in-the-whole, that appears to be proscrib-

\footnotetext{
${ }^{1}$ Francois Lurçat, "Understanding Quantum Mechanics with Bohr and Husserl," in Rediscovering Phenomenology: Phenomenological Essays on Mathematical Beings, Physical Reality, Perception and Consciousness, ed. Luciano Boi, Pierre Kerszberg, and Frederic Patras (Dordrecht: Springer, 2007), pp. 254-255.

${ }^{2}$ Carroll, Sean Carroll: The Many Worlds of Quantum Mechanics.
} 
ing the experience of wave functions. It is not, assessed hermeneutic-phenomenologically, because wave functions are not of reality, as Bohr asserts, or they belong to a different region of reality, as Lurçat implies.

Wave functions are contained within the universe. If they did not, the Schrödinger equation would have nothing to calculate and there would be

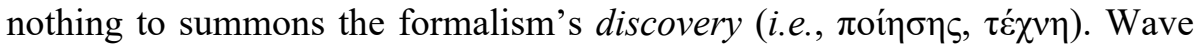
functions are not unavailable to consciousness or Da-sein. They do not belong to a separate (quantum) reality, have no reality, or reside in a different sphere of reality. Da-sein cannot experience wave functions or "physically" or "objectively" access them because it intrinsically lacks the power to bring them to light $\mathrm{t} /$ here, in transcendence. The standard interpretation overlooks this more economical solution because it neglects to consider, as Mermin points out, "questions about the limitations in how we think and how we are capable of apprehending the world." Moreover, it compounds the errancy by supplanting opportunities to come to the consideration with ad hoc postulates-such as those contending the investigation of the foundations of quantum mechanics is meaningless or wave functions evolve according to the physical laws embodied in the Schrödinger equation but do not subscribe to the same laws when they are measured ${ }^{2}$ - that further short-circuit the human power to think and know.

"The standard approach requires an external observer for a system in a quantum state and, therefore, is unable to deal with the quantum state of the whole Universe."3 Vaidman's observation underscores an inconsistency within the standard interpretation hermeneutical-phenomenology associates with fallenness (Verfallen), or Da-sein's absorption in beings. ${ }^{4}$ Hermeneuticphenomenology surmises a correspondence between Da-sein's comprehension of being and its comportment with beings. ${ }^{5}$ It correlates $\mathrm{Da}$-sein's understanding of "is" with the way it encounters beings and the World in everyday, concrete living and, hence, comprehends phenomena. The designation of "fallenness" is not a "negative evaluation," however. It signifies an expression of

\footnotetext{
${ }^{1}$ Mermin, Boojums All the Way Through: Communicating Science in a Prosaic Age, p. 199.

${ }_{2}$ David Z Albert, Quantum Mechanics and Experience (Cambridge: Harvard Univesity Press, 1994), p. 79.

${ }^{3}$ Vaidman, "On Schizophrenic Experiences of the Neutron or Why We Should Believe in the Many-Worlds Interpretation of Quantum Theory," p. 260.

${ }^{4}$ Heidegger, Being and Time, pp. 219-224.

${ }^{5}$ Richardson, Heidegger: Through Phenomenology to Thought, p. 38.

${ }^{6}$ Heidegger, Being and Time, p. 222.
} 
factical life. Da-sein, as exhibited by hermeneutic-phenomenology, is dependent on beings to accomplish itself. It relies on things to be. It is referentially dependent on their meaning (i.e., human being is the being-of-t/here) and compelled to control beings to survive and live. Its radical dependence on beings evokes an excessive concern with things that tends to deflate its concern for being. It ineluctably drags $\lambda$ ó $\gamma_{0} \varsigma$ into a mode of comprehending that forgoes the meaning of "is" and attenuates its openness to beings-in-the-whole. Hermeneutic-phenomenology corresponds fallenness to a mode of ontological blackout. It assesses the phenomenon effects a way of experiencing that appropriates the World as a discrete object (e.g., a classical or local thing) populated by discrete subjects (e.g., observers) and objects (e.g., measuring devices). Fallen $\mathrm{Da}$-sein, it postulates, is closed to its transcendence. It is blind to its ownmost meaning, or the being-of-t/here, and comes to pass as a World governed by subject-object (metaphysical) dualisms.

Hermeneutic-phenomenology (and phenomenology generally) cannot legitimately propose to answer "the question of why and how our experience of a 'classical' world emerges from quantum mechanics." The query is entirely unrelated to its purpose and categorically excluded from its scope. It can, however, legitimately propose to answer the question of the standard interpretation's persistent rendition of the World in classical terms. It can also deliver a response that is perhaps more fundamental than the transcendental-phenomenological understanding associating the standard formulation with a commitment to the natural thesis. The standard interpretation's insistence "on classical or other local descriptions of physical reality," ${ }^{2}$ as Zeh describes it, could be an effect of fallenness and the way Da-sein factically endures the World. Surmised hermeneutic-phenomenologically, the standard interpretation's characteristic allegiance to "discreteness," ${ }^{3}$ to a classical conception of reality and the "intuitive understanding of how the world works," could be correlate to Da-sein's absorption in beings as well as the limitations and errancy endemic

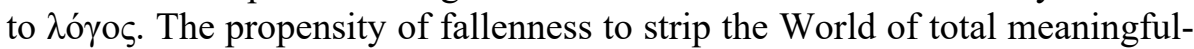
ness and compel Da-sein to assume a dualistic-mode of comprehending may be prereflectively positioning $\lambda$ ó ${ }^{\circ} \varsigma$ against the possibility that "a global wave function," which laterally corresponds with the rendition of the World as a

\footnotetext{
1 Schlosshauer, "Decoherence, the Measurement Problem, and Interpretations of Quantum Mechanics."

${ }^{2}$ Zeh, "Quantum Discreteness Is an Illusion,” p. 1492.

${ }^{3}$ Ibid., p. 1477.

${ }^{4}$ Carroll, Sean Carroll: The Many Worlds of Quantum Mechanics.
} 
beings-in-the-whole, "may be sufficient to describe reality." It, in conjunction with limitations and errancy intrinsic to $\lambda$ ó $\gamma o \varsigma$, presents itself as a possible principal antecedent evoking the standard interpretation's persistent "prejudice that reality must consist of local events." It offers itself as a root cause of the "paradoxes" the standard interpretation commonly confronts in "many quantum experiments," and which, according to Zeh:

appear as paradoxes only if one subscribes to the folklore that reality consists of local events (which have to occur spontaneously and 'outside the laws of Nature" according to Pauli)." These weird phenomena were in fact all predicted by consistently using the nonlocal wave function [the Schrödinger equation]. ${ }^{3}$

MWI answers the measurement problem by way of its response to the standard interpretation. Its solution to the questions of "wave function collapses," "measurements," and "observers" and its association of branching universes with the evolution of the wave function are commensurate. A phenomenological reading of the standard interpretation is also, then, by effect, a reading of the hermeneutics that provokes Everett to project-open (think) the wave function. The two are contemporaneous. They go hand in hand, and reveal Everett's thinking to be aligned with phenomenological thinking. This assertion does not say Everett applies phenomenology or, like London and Bauer's monograph, is in any way familiar with or sensitive to the method. It suggests his thinking corresponds with a phenomenological course. Phenomenology is not a philosophy, and it is not metaphysics. It is the effort to think as such. It strives

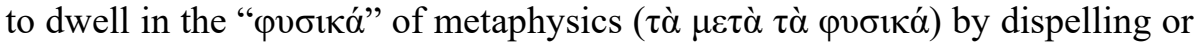
resisting inclinations to generate or commit to a " $\mu \varepsilon \tau \alpha$. ." It labors to extend the parameters endemic to comprehending, suspend the prejudices and prejudgments that commonly accompany discovery and knowledge, and discharge thinking's disclosing-saying power. Phenomenological thinking, or thinking as such, is the endeavor to let the truth of the matter of Da-sein commandeer $\lambda$ ó ${ }^{\circ} \varsigma$. It is not alien to scientific discovery, but instead corresponds to its impetus.

Although phenomenology does not remove itself from the scientific enterprise, including contemporary physics, it does not do quantum mechanics, and, in this instance, purposefully confines itself to exposing the hermeneutics surrounding the Schrödinger formalism. It strives to suspend extraneous articulations of the quantum world by "putting aside," as Bell writes in his criticism

${ }^{1}$ Zeh, "Quantum Discreteness Is an Illusion," p. 1478.

${ }^{2}$ Ibid., p. 1488.

${ }^{3}$ Ibid., p. 1489. 
of the Copenhagen interpretation, "preconceptions and listening to what is actually said" then listening "a little harder." Transcendental-phenomenology works toward this end by reducing the quantum mechanical rendition of the wave function to its basic meaning and letting that experience imbue intentionality. Hermeneutic-phenomenology takes a different, but not unrelated, path and arrives at a commensurate outcome. It strives to let the ownmost of the evolution of the wave function steer thinking and language to the phenomenon's self-disclosure. Both courses are consistent with MWI's approach to the measurement problem, as evidenced by its commitment to conceptual simplicity, which does not, as Everett writes, necessarily mean "ease of use."

A good example of the distinction is the theory of general relativity, which is conceptually quite simple, while enormously cumbersome in actual calculations. Conceptual simplicity...has the property of increasing confidence in a theory. A theory containing many ad hoc constants and restrictions, or many independent hypotheses, in no way impresses us as much as one which is largely free of arbitrariness. ${ }^{2}$

Features of MWI that correspond with the phenomenological rendition of its matter include its hermeneutical point of departure, its effort to let the truth of the Schrödinger equation drive its propositions, and its confrontation with the natural thesis. The notion of a wave function of the universe, MWI's interpretive start-point, parallels the hermeneutic-phenomenological discernment of reality as beings-in-the-whole. The interpretations are isomorphically commensurate. MWI, like phenomenology, rejects dualistic interpretations of reality and strives to mitigate their tendency to creep into the interpretation of things. To borrow again from Mermin, it opposes opportunities for "powerful but flawed verbal and mental tools we once took for granted" to "continue to infect our thinking in subtly hidden ways." 3 The theory asserts all wave functions are encompassed by the one quantum universe, or the "one global superposition," 4 and from there explains their evolution. It liberates itself from notions of wave function collapses, measurements, and observers by rejecting specious temptations to localize subjects and objects. For MWI, the universe

\footnotetext{
${ }^{1}$ Bell, "Bertlmann's Socks and the Nature of Reality," p. 144.

${ }^{2}$ Everett, "The Theory of the Universal Wave Function," pp. 135-136.

${ }^{3}$ Mermin, Boojums All the Way Through: Communicating Science in a Prosaic Age, p. 199.

${ }^{4}$ Zeh, "Quantum Discreteness Is an Illusion," p. 1483; "Basic Concepts and Their Interpretation."
} 
comprises "everything." It is as an inclusive totality of essentially related things fundamentally continuous with each other. It is a unity that evolves as such. MWI interprets the universe as a single transformation rather than discerning it as a conglomerate of disconnected processes.

In MWI "the universe as a whole is considered." The theory abandons a classical (dualistic) point of departure. Instead, as Schlosshauer observes, it assumes (a) "the existence of a total state $|\Psi\rangle$ representing the state of the entire universe" and (b) upholds "the universal validity of the Schrödinger evolution." These two notions constitute its "central idea." MWI resists spontaneous impulses to drift into metaphysical explanations of reality by appropriating the wave function as an integral part of the macroscopic system and, hence, the universal wave function. ${ }^{3}$ It says wave functions decohere when they entangle with a macroscopic system. It says nothing about wave function collapses, measurements, or observers. The motivation to localize quantum states is dispelled because, as Bousso and Susskind note, the "subjectivity of decoherence," that is, the quantum state of an observer and measurement relative to the evolution of the wave function, is understood to be "immersed in a much larger system," the "environment." "From the "standpoint" of MWI "it is not so much the system which is affected by an observation as the observer, who becomes correlated to the system." 6

Vaidman writes:

The quantum theory of the wave function of the Universe is a very successful deterministic theory fully consistent with our experimental evidence. However, it requires accepting that the world we experience is only part of the reality and there are numerous parallel worlds. ${ }^{7}$

\footnotetext{
${ }^{1}$ Sheldon Goldstein and Nino Zahghi, "Reality and the Role of the Wave Function in Quantum Theory," in The Wave Function: Essays in the Metaphysics of Quantum Mechanics,, ed. Alyssa Ney and David Z Albert (Oxford: Oxford University Press, 2013), p. 93.

${ }^{2}$ Schlosshauer, "Decoherence, the Measurement Problem, and Interpretations of Quantum Mechanics," p. 1288.

${ }^{3}$ Carroll and Sebens, "Many Worlds, the Born Rule, and Self-Locating Uncertainty."

${ }^{4}$ Raphael Bousso and Leonard Susskind, "Multiverse Interpretation of Quantum Mechanics," Physical Review 85, no. 4 (2012), p. 2.

${ }^{5}$ Carroll, Sean Carroll: The Many Worlds of Quantum Mechanics.

${ }^{6}$ Everett, "The Theory of the Universal Wave Function," p. 116.

${ }^{7}$ Lev Vaidman, "Quantum Theory and Determinism," Quantum Studies: Mathematics and Foundations 1 (2014), p. 5.
} 
The observation is correct from the perspectives of transcendental- and hermeneutic-phenomenology. MWI is at odds with the comprehension of the World lived within the general standpoint. Its affirmation is contingent on a suspension of the natural thesis. It is premised on the self-given understanding that the World is from its outset a totality. "The universe, as Everett views it, is clearly to be thought of as one vast, deterministically evolving entangled system," Lockwood writes. ${ }^{1}$ The theory unfolds from an interpretation of reality that is symmetrically consistent with the hermeneutic-phenomenological discernment of World as the one World all Da-seins together are. It assumes a point of departure that is commensurate with the rendition of the World as beings-in-the whole. It is aligned with the understanding there is only one World and each and every Da-sein is t/here with/in it bound into a whole in/through being. The thesis postulating branching universe commences from the understanding that this universe is one phenomenon and everything and everyone it encompasses are included in and continuous with it.

Wallace says the "natural" answer to the question of what should be expected "from an 'interpretation' of quantum mechanics" is a "set of instructions" immanent to it that say "how to understand that theory." Everett fulfills this mandate by taking the "validity" of wave mechanics "seriously" without introducing "any new postulates" ${ }^{3}$ His "pure wave mechanics," a perspective that assumes "no fundamental distinction between 'measuring apparata' and other physical systems," "including quantum ones and the universe, ${ }^{4}$ frees the ownmost meaning of the Schrödinger formalism to say from itself what the wave function is: a "fundamental entity" that "at all times" obeys a "deterministic wave equation." The theory does not assume any "separate rules" concerning "wave function collapse," "quantum measurement," or "additional hidden variables." It is "empirically faithful," "consistent," "simple," and

\footnotetext{
${ }^{1}$ Michael Lockwood, “"Many Minds.' Interpretations of Quantum Mechanics," The British Journal for the Philosophy of Science 47, no. 2 (1996), p. 168.

2 David Wallace, "On the Plurality of Quantum Theories: Quantum Theory as a Framework, and Its Implications for the Quantum Measurement Problem," in Scientific Realism and the Quantum, ed. Steven French and Juha Saatsi (Oxford: Oxford University Press, 2019), p. 85.

${ }^{3}$ Hugh Everett, "Probability in Wave Mechanics," in UCISpace @ the Libraries (Irvine: University of California, Irvine Libraries, 1955), p. 9.

4 "The Theory of the Universal Wave Function," pp. 8, 53.

5 "Probability in Wave Mechanics," p. 9.

${ }^{6}$ Sebens and Carroll, "Self-Locating Uncertainty and the Origin of Probability in Everettian Quantum Mechnics," p. 26.
} 
"comprehensive" and bars "metaphysical" obligations. ${ }^{1}$ Relying exclusively on the truth of the Schrödinger equation, and "without drawing on any external metaphysics or mathematics other than the standard rules of logic," Everett shows "the mathematical formalism of the quantum theory is capable of its own interpretation." ${ }^{2}$ His hermeneutical point of departure precludes the "contradiction" Albert illustrates between the "dynamics" illumed by the Schrödinger formalism and the "postulate of collapse" commonly associated with the standard formulation. It forestalls the interpretive dissonance that ensues between an idea Albert, who French also quotes, ${ }^{3}$ says "seems to be right about what happens when we make measurements" (wave function collapse) and an equation (the Schrödinger formalism) that seems "to be bizarrely wrong about what happens when we make measurements" and yet "seems to be right about what happens whenever we aren't making measurements."

MWI instances the disruptive power of thinking. It follows a trajectory commensurate with an upending of prereflective and commonsense notions about the way things are and should be to let them disclose-say their own significance. Not only does it assert this universe is not the only universe and it and every copy of it are constantly branching other universes, but everyone and everything in each universe are also copied. More than just schizophrenia with a vengeance, as Dewitt says, it is a Copernican revolution on steroids. The theory has profound ontological, psychological, and cosmological implications. It challenges taken-for-granted conceptions of reality, subjectivity, individuality, values, and ultimate meaning. It displaces notions about the uniqueness persons commonly attribute to themselves and challenges contemporary idolizations of the self. It was initially believed "bizarre," the stuff of "scientific fiction," until more recently when it has garnered support within the fields of cosmology and quantum information. ${ }^{5}$ Everett anticipated the substance of these reactions. He recognized his theory would be "abhorrent to many individuals that there should not be a single unique state for them (in the world view)," even though the "interpretation explains all subjective feelings quite adequately and is consistent with all observations."

1 Jefffey A. Barrett, "Everett's Pure Wave Mechanics and the Notion of Worlds," European Journal for Philosophy of Science 1 (2011), pp. 275, 278, 300.

${ }^{2}$ DeWitt, "Quantum Mechanics and Reality," p. 33.

${ }^{3}$ French, "From a Lost History to a New Future: Is a Phenomenological Approach to Quantum Physics Viable?," p. 207.

${ }^{4}$ Albert, Quantum Mechanics and Experience, p. 79.

${ }^{5}$ Vaidman, "Quantum Theory and Determinism," p. 24.

${ }^{6}$ Hugh Everett, 1980. 
The responses MWI commonly evokes are apparent effects to the way Everett thinks the evolution of the wave function. They are ostensible reactions to his confrontation with the natural thesis. MWI connotes a suspension of taken-for-granted, classical formulations about the quantum world and an effort to inabide the essential meaning of the Schrödinger equation. His interpretation of the evolution of the wave function corresponds with the way phenomenology thinks the meaning emitted by the Schrödinger formalism. MWI brackets commonsense notions of locality and lets the Schrödinger equation freely disclose-say what the wave function is doing. It corresponds to a turning to the things themselves that challenges what Everett says is a conservatively "safe" and "overcautious" interpretation that has impeded efforts to reveal the workings of the universe. ${ }^{1}$ The theory asserts that "all that happens in measurement" is the nucleation of a "quantum correlation" and decoherence of the aggregate system. ${ }^{2}$ Heeding these phenomena "involves," as Barrett writes, "accepting the physical existence of many splitting worlds containing physical copies of observers and the objects they observe." More fundamentally, it requires, interpreted transcendental-phenomenologically, suspending intuitive notions constituted in the natural thesis that spontaneously contradict the "predictions of quantum mechanics" and the "unitary evolution prescribed by the Schrödinger equation." ${ }^{4}$ It means bracketing the general standpoint to dispel the "weirdness" that Zeh says "is merely a consequence of the traditional attempt to describe the observed world in classical terms" and allowing reality to be described quantum mechanically. ${ }^{5}$ It means, interpreted hermeneutic-phenomenologically, resolutely yielding $\lambda$ ó $\gamma \circ \varsigma_{\text {s }}$ to the essential meaning of the Schrödinger equation to allow the understanding of branching universes to be entirely "plausible" and " normal.,"6

\section{Concluding remarks}

A phenomenological reading of MWI's response to the measurement problem, the rendition of the interpretation either transcendental-phenomenologically or

1 "The Theory of the Universal Wave Function," p. 111.

${ }^{2}$ Lockwood, “'Many Minds.' Interpretations of Quantum Mechanics," pp. 165-166; Zeh, "Basic Concepts and Their Interpretation," p. 31.

${ }^{3}$ Barrett, "Everett's Pure Wave Mechanics and the Notion of Worlds," p. 278.

${ }^{4}$ Lockwood, “'Many Minds.' Interpretations of Quantum Mechanics," p. 161.

5 H. Dieter Zeh, "The Role of the Observer in the Everett Interpretation," NeuroQuantology 11, no. 1 (2013), p. 103.

${ }^{6}$ Ibid., p. 103. 
hermeneutic-phenomenologically, does not disagree with MWI's answer to the question of the evolution of the wave function. Rather, it is remarkably aligned with it. It, like MWI, strives to report that which the phenomenon shows from itself to be. It methodologically agrees with Everett's austere reading of the mathematics, which "says there's a wave function and there is nothing else." Its acknowledges the empirical support MWI derives from the understanding the Schrödinger formalism has been robustly corroborated and thus far provides the most accurate and reliable explanation of quantum states. It finds no apparent reason to dismiss the equation's success passing intersubjective tests to falsify it. It discloses a symmetry between MWI's rendition of the universal wave function and the phenomenological rendition of beings-inthe-whole. It also reveals the thinking the theory embodies is consistent with a suspension of the natural thesis. Its reading of MWI agrees with the confidence the theory derives from its unforgiving appropriation of the Schrödinger equation. It also agrees with the consistency of its association of branching universes with the evolution of the wave function insofar as that understanding comes from the formalism itself. It recognizes the challenges the theory faces testing its prediction of branching universes because of their posited "dynamical decoupling under decoherence." ${ }^{2}$ It does not accept this thesis as justification to avoid trying to test (falsify) the theory. Neither does Carroll, who openly admits MWI is "not a fully developed theory yet," and the task of "matching" it to what is seen in the "experimental world" has not been "completely finished." Moreover, although MWI has implications that, at least for now, cannot be tested, Carroll further explains, many of its assumptions and some of its predications are indeed available to experiential falsification. ${ }^{3}$

A phenomenological reading of the standard interpretation implicitly endorses the thinking associated with MWI. It reveals the errancies within the standard interpretation's response to the measurement problem and does not support its apparently ad hoc assertions positing wave function collapses. It corresponds the inconsistencies it discloses in the standard formulation to a failure to inabide the ownmost meaning of the Schrödinger equation and let it freely disclose-say what the wave function is doing. It sources the discrepancies to a dualistic rendition of reality that alienates $D a$-sein from itself (beingsin-the-whole) and increases the susceptibility of $\lambda$ ó $\gamma$ os to generate or accept metaphysical theses explaining why only one of a wave function's probable

\footnotetext{
${ }^{1}$ Carroll, Episode 63: Solo: Finding Gravity within Quantum Mechanics.

${ }^{2}$ Zeh, "Basic Concepts and Their Interpretation," p. 33.

${ }^{3}$ Carroll, Sean Carroll: The Many Worlds of Quantum Mechanics.
} 
values is observed when a quantum system is measured. It exposes the hermeneutical shortcomings of assertions proscribing the investigation of the foundation of quantum mechanics and describing the enterprise as meaningless because wave functions are "physically" or "objectively" inaccessible. It supports the more parsimonious thesis asserting wave functions exceed the capacity of $\lambda$ ó $\gamma o \varsigma$ to endure (experience) them-another way to say this phenomenologically, specifically, being-historically, is: the meaning of the wave function, which Da-sein is, includes its hiddenness. Proscriptions against the investigation of the foundation of quantum mechanics or the identification of the endeavor as meaningless do not freely shine forth from the meaning emanating from the ownmost of the Schrödinger formalism. They imply an arbitrary interpretation of reality, an abandonment of thinking, and a reification of $\lambda$ ó $\gamma$ os.

\section{References}

Albert, David Z. Episode 45: David Albert on Quantum Mechanics and the Problems with Many-Worlds. Podcast audio. Mindscape 2019. https://www.preposterous universe.com/podcast/2019/03/04/episode-36-david-albert-on-quantummeasurement-and-the-problems-with-many-worlds/.

—. Quantum Mechanics and Experience. Cambridge: Harvard Univesity Press, 1994.

Albert, David Z, and Barry Loewer. "Intepreting the Many Worlds Interpretation." Synthesis 77, no. 2 (1988): 195-213.

Barrett, Jefffey A. "Everett's Pure Wave Mechanics and the Notion of Worlds." European Journal for Philosophy of Science 1 (2011): 277-302.

Becker, Adam. What Is Real? The Unfinished Quest for the Meaning of Quantum Mechanics. New York: Basic Books, 2018.

Becker-Larsen, Lars. "Atomic Physics and Reality.” 40:14. Denmark, 1985.

Bell, John S. "Bertlmann's Socks and the Nature of Reality." In Speakable and Unspeakable in Quantum Mechanics: Collected Papers on Quantum Philosophy, edited by John. S. Bell, 139-58. Cambridge: University Press, 1991.

Bousso, Raphael, and Leonard Susskind. "Multiverse Interpretation of Quantum Mechanics." Physical Review 85, no. 4 (15 February 2012): 1-22.

Carroll, Sean. Episode 55: A Conversation with Rob Reid on Quantum Mechanics and Many Worlds. Podcast audio. Mindscape 2019. https://www.preposterous universe.com/podcast/2019/07/15/55-a-conversation-with-rob-reid-on-quantummechanics-and-many-worlds/. 
—. Episode 63: Solo: Finding Gravity within Quantum Mechanics. Podcast audio. Mindscape 2019. https://www.preposterousuniverse.com/podcast/2019/09/ 09/63solo-finding-gravity-within-quantum-mechanics/.

—. Sean Carroll: The Many Worlds of Quantum Mechanics. New Scientist 2018. https://youtu.be/p7XIdFbCQyY.

-. Something Deeply Hidden: Quantum Worlds and the Emergence of Spacetime. Dutton, 2019.

Carroll, Sean M., and Charles T. Sebens. "Many Worlds, the Born Rule, and SelfLocating Uncertainty." In Quantum Theory: A Two-Time Success Story: Yakir Aharonov Festschrift, edited by Daniele C. Struppa and Jeffrey M. Tollaksen, 15769. Milano: Springer, 2014.

Deutsch, David. “Comment on 'Many Minds' Interpretations of Quantum Mechanics by Michael Lockwood."' British Journal for the Philosophy of Science 47 (1996): 222-28.

DeWitt, Bryce S. "Quantum Mechanics and Reality." Physics Today 23, no. 9 (September 1970): 30-35.

Einstein, Albert, Boris Podolsky, and Nathan Rosen. "Can Quantum-Mechanical Description of Physical Reality Be Considered Complete?" Physical Review 47 (1935): 777-80.

Emad, Parvis. "On the Inception of Being-Historical Thinking and Its Unfolding as Mindfulness.” Heidegger Studies 16 (2000): 55-71.

-. On the Way to Heidegger's Contributions to Philosophy. Madison: The University of Wisconsin Press, 2007.

Everett, Hugh. 1980.

—. "Probability in Wave Mechanics." In UCISpace@ the Libraries, 9. Irvine: University of California, Irvine Libraries, 1955.

- . "The Theory of the Universal Wave Function." In The Many Worlds Interpretation of Quantum Mechanics, edited by Bryce S. DeWitt and Neill Graham, 3-140. Princeton: Princeton University Press, 1973.

French, Steven. "From a Lost History to a New Future: Is a Phenomenological Approach to Quantum Physics Viable?" In Phenomenological Approaches to Physics, edited by Harald A. Wiltsche and Phillip Berghofer, 205-25. Cham: Springer, 2020.

Friebe, Cord. "The Measurement Problem. Minimal and Collapse Interpretations." In The Philosophy of Quantum Physics, edited by Cord Friebe, Meinard Kuhlmann, Holger Lyre, Paul M. Näger, Oliver Passon and Manfred Stöckler, 39-71. Cham: Springer, 2018.

Fuchs, Christopher A., and Asdher Peres. "Quantum Theory Needs No 'Interpretation.'” Physics Today 53, no. 3 (2000): 70-71.

Goldstein, Sheldon, and Nino Zahghi. "Reality and the Role of the Wave Function in Quantum Theory." In The Wave Function: Essays in the Metaphysics of Quantum Mechanics, edited by Alyssa Ney and David Z Albert, 91-109. Oxford: Oxford University Press, 2013. 
Heidegger, Martin. Being and Time. Translated by John Macquarrie and Edward Robinson. New York: Harper \& Row, Publishers, 1962.

- Contributions to Philosophy (from Enowning). Translated by Parvis Emad and Kenneth Maly. Bloomington: Indiana University Press, 1999.

- Mindfulness. Translated by Parvis Emad and Thomas Kalary. London: Continuum International Publishing Group, 2006.

- What Is Called Thinking? Translated by Fred D. Wieck and J. Glenn Gray. New York: Harper \& Row, Publisherd, 1968.

Husserl, Edmund. Cartesian Meditations: An Introduction to Phenomenology. Translated by Dorion Cairns. Dordrecht: Kluwer Academic Publishers, 1999.

- The Crisis of European Sciences and Transcendental Phenomenology: An Introduction to Phenomenological Philosophy. Translated by David Carr. Evanston: Northwestern University Press, 1970.

- The Idea of Phenomenology. Translated by William P. Alston and George Nakhnikian. Dordrecht: Kluwer Academic Press, 1990.

—. Ideas: General Introduction to Pure Phenomenology. London: George Allen \& Unwin Ltd, 1931.

Kalary, Thomas, and Frank Schalow. "Attunement, Discourse, and the Onefold of Hermeneutic Phenomenology: Recent Heidegger-Literature and a New Translation of His Work in Critical Perspective." Heidegger Studies 27 (2011): 199-210.

Kovacs, George. "The Idea of Hermeneutics in Heidegger." Existentia 10, no. 1-4 (2000): 41-50.

-. Thinking and Be-Ing in Heidegger's Beiträge Zur Philosophi (Vom Ereignis). Bucharest: Zeta Books, 2015.

Lockwood, Michael. “'Many Minds.' Interpretations of Quantum Mechanics.” The British Journal for the Philosophy of Science 47, no. 2 (1996): 159-88.

London, Fritz, and Edmond Bauer. "The Theory of Observation in Quantum Mechanics." In Quantum Theory and Measurement, edited by John Archibald Wheeler and Wojciech Hubert Zurek. Princeton: Princeton University Press, 1983.

Lurçat, Francois. "Understanding Quantum Mechanics with Bohr and Husserl." In Rediscovering Phenomenology: Phenomenological Essays on Mathematical Beings, Physical Reality, Perception and Consciousness, edited by Luciano Boi, Pierre Kerszberg and Frederic Patras, 229-58. Dordrecht: Springer, 2007.

Merleau-Ponty, Maurice. Phenomenology of Perception. Translated by Colin Smith. London: Routledge \& Kegan Paul, 1962.

Mermin, N. David. Boojums All the Way Through: Communicating Science in a Prosaic Age. Cambridge: Cambridge University Press, 1990.

Nakhnikian, George. "Introduction." In The Idea of Phenomenology, ix-xxii. Dordrecht: Kluwer Academic Press, 1990.

Richardson, William J. Heidegger: Through Phenomenology to Thought. 2nd ed. The Hague: Martinus Nijhoff, 1967. 
Schalow, Frank. "Introduction." In Heidegger, Translation, and the Task of Thinking: Essays in Honor of Parvis Emad, edited by Frank Schalow. Contributions to Phenomenology, 11-47. New York: Springer, 2011.

Schlosshauer, Maximilian. "Decoherence, the Measurement Problem, and Interpretations of Quantum Mechanics." Reviews of Modern Physics 76, no. 4 (October 2004): 1267-305.

Schutz, Alfred. “On Multiple Realities." Philosophy and Phenomenological Research 5, no. 4 (June 1945): 533-76.

Sebens, Charles T., and Sean M. Carroll. "Self-Locating Uncertainty and the Origin of Probability in Everettian Quantum Mechnics." The British Journal for the Philosophy of Science 69, no. 1 (2018): 25-74.

Vaidman, Lev. "On Schizophrenic Experiences of the Neutron or Why We Should Believe in the Many-Worlds Interpretation of Quantum Theory." International Studies in the Philosophy of Science 12, no. 3 (1998): 245-61.

-. "Quantum Theory and Determinism." Quantum Studies: Mathematics and Foundations 1 (2014): 5-38.

Wallace, David. "On the Plurality of Quantum Theories: Quantum Theory as a Framework, and Its Implications for the Quantum Measurement Problem." In Scientific Realism and the Quantum, edited by Steven French and Juha Saatsi, 78102. Oxford: Oxford University Press, 2019.

Zeh, H. Dieter. "Basic Concepts and Their Interpretation." In Decoherence and the Appearance of a Classical World in Quantum Theory, edited by Erick Joos, H. Dieter Zeh, Claus Kiefer, Domenico Giulini, Joachim Kupsch and Ion-Olimpiu Stamatescu, 7-40. Heidelberg: Springer-Verlag, 2003.

—. "Quantum Discreteness Is an Illusion." Foundation of Physics 40 (2010): 147693.

-. "The Role of the Observer in the Everett Interpretation." NeuroQuantology 11, no. 1 (March 2013): 97-105.

Zurek, Wojciech H. "Decoherence and the Transition from Quantum to Classical." Physics Today 44, no. 10 (October 1991): 36-44. 